\title{
LOS GEMELOS QUE SE INTERCAMBIAN LA INMORTALIDAD
}

\section{Rafael Rodríguez Diaz}

$\mathrm{L}$

a geminación de una estrella hace referencia a la existencia de una estrella doble, o gemela, ahi donde a simple vista aparece un solo astro. (Comellas: 41). Pues bien, en la constelación de Géminis tenemos un caso curioso. La constelación se llama así porque sus dos estrellas principales - Cástor y Póluxparecen gemelos: tienen casi el mismo brillo y están muy cerca la una de la otra. Pero, además, una de ellas - Cástor- es estrella doble. De donde resulta que en la constelación de Géminis hay una "doble" geniinnción; quizás, por eso, en castellano, no conten'tos con el nombre Gémini, como debería ser -porque es el plural del nombre, en latín - (Ruiz de Elvira: 475), le agregaron la s para recalcar que se está ante un caso reduplicativo de Gemelos. Géminis, pues, es la constelación de los dobles Gemelos.

Estrellas de esas constelación son: Cástor $(\alpha)$, Pólux $(\beta)$, Alhena $(\gamma)$, Wasat $(\delta)^{*}$, Mebsuta $(\varepsilon)$, Mekbuda $(\zeta)^{* *}$, Propus $(\eta)^{* * *}$, Tejat $((1)$. La figura que forman estas estrellas es la siguiente:

- Alhena es la gamma Geminorum; significa: "una marca" en el pie de Pólux, o también: "marca impresa con hierro candente en el pescuezo del camello", o: "el caminante orgulloso". Wesat es la delta Geminorum; significa: "la de en medio". (Chartrand: 148; De Gortari: 106.

*4 Mebsuta es la épsilon Geminorum; significa: "el brazo tendido" o "la extendida". Mekbuda es la zeta Geminorum; significa: "el brazo contraido del león". (de Gortari: 107).

**4 Propus es la eta Geminorum; señala el pie izquierdo de Cástor. (Chartrand: 


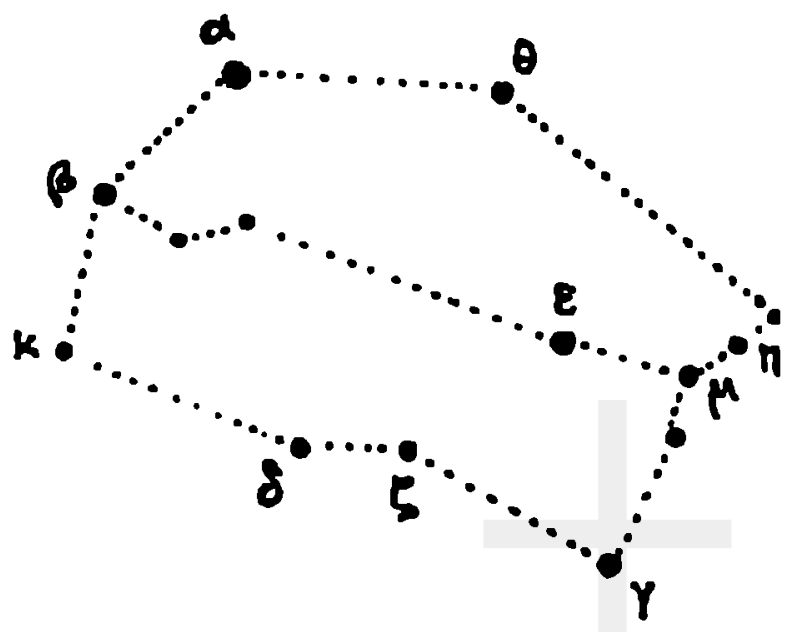

Un imaginativo observador del firmamento puede ver en esta constelación la figura de dos muchachos parados el uno al lado del otro. El sol está en esta constelación zodiacal desde junio 21 a julio 21. Aqui tienen también su punto de irradiación los meteoros Gémini. (Chartrand: 148).

Los relatos mitológicos que dan vida a los Mellizos o Gemelos se van entretejiendo hasta dar por resultado un complicado tapiz. Recorramos, pues, los hilos que conforman ese peculiar tejido.

Comienza todo con una historia que ya conocemos en parte. A resultas de la unión amorosa de Zeus, convertido en cisne, con Leda, esta puso un huevo; de él nacieron Helena, Cástor y Pólux. Una variante acota que Leda puso, más bien, un segundo huevo del que nacieron Helena y Clitemnestra. (Graves: I, 225).

Pero ya habiamos hecho notar que son muchas las variantes acerca de la procedencia de Cástor y Pólux. Una más señala que Cástor y Clitemnestra son hijos de Tindáreo, mientras que Pólux y Helena lo son de Zeus. (Graves: Ibid; Ruiz de Elvira: 410). Y

Ibid.). Esta estrella se ha distinguido por sus variaciones de intensidad; pero, sobre todo, se ha hecho célebre Propus porque en sus proximidades se encontraba el planeta Urano cuando fue descubierto por Herschel el 13 de marzo de 1781. Propus ha servido largo tiempo de comparación para determinar el movimiento de aquel planeta. (Historia Universal lustrada: $X X V, 1197$ ). 
esto último está más en consonancia con lo que conoceremos luego acerca de los Gemelos.

El hecho de que haya tantas versiones en este asunto se debe a que la leyenda de Cástor y Pólux pertenece a la primitiva mitologia helénica; por eso, el nombre de los dos Gemelos se encuentra asociado a gran número de tradiciones locales. Más tarde, esas tradiciones se procuraron conciliar reuniendo los distintos elementos en la leyenda principal (Historia Universal Ilustrada: XII, 353).

Como nota curiosa apuntemos que también en otras culturas se veneraba a una pareja equivalente a la de Cástor y Pólux. Así, en el panteón védico estaban los Aswins, y en varios himnos del Rigveda existen invocaciones a los dos gemelos hijos de Vivasoat (el cielo) y de Saranyú (la tierra). Los celtas dedicaron culto especial a los Dióscuros, a los que tenían por hijos del Océano. Los germanos adoraban a una pareja de gemelos de nombre Alcis. En Australia, los bosquimanos creen en dos hembras, hijas del gran antilope. (Historia Universal Ilustrada: XII, 352).

Pues bien, Cástor y Pólux nacieron en la ladera del monte Taigeto, desde donde fueron llevados por Hermes a la residencia de Tíndaro (Tindáreo) en Pelana. Ahi se educaron juntos y se convirtieron en inseparables compañeros, caracterizándose por su extraordinario y mutuo amor fraternal. Cástor se destacó como sol: dado y domador de caballos; Pólux llegó a ser el mejor púgil de su época. Por sus respectivas habilidades los dos hermanos ganaron premios en los Juegos Olímpicos y llegaron a ser el orgullo de Esparta (Historia Universal Dustrada: XII, 353; Graves: I, 305).

Incluso, se dice que Cástor le dio al joven Héracles o Hércules lecciones de esgrima; le instruyó en el manejo de las armas, las tácticas de la infantería y caballería, y los rudimentos de la estrategia de la guerra. (Graves: II, 113).

Por todas sus hazañas, Pólux fue tenido como el prototipo y protector de los atletas; mientras que Cástor lo fue de los jinetes y domadores de potros. (Gebhardt: I, 138).

Muchas fueron las aventuras en las que participaron juntos los Gemelos. La primera de ellas tuvo que ver con el rescate de su hermana Helena. Esta fue raptada por Teseo y Pirítoo, su hermano 
gemelo. Los Dióscuros, entonces, al mando de un ejército, asolaron Atica y lograron rescatar a su hermana. También se llevaron consigo como rehén a la madre de Teseo, poniendo en lugar de ella en el trono de Atica a Menestea; esta introdujo en el pais el culto a los dióscuros. (Historia Universal Mustrada: XII, 353).

Mientras los Dióscuros salvaban a Helena, Teseo y Pirítoo habían descendido al Tártaro; ahi permanecieron cuatro años, y tuvo que intervenir Hércules para salvarlos de la Silla del Olvido: unos asientos de piedra calientes. Sólo que al arrancarlos de sus asientos, partes de las nalgas se les desprendieron a Teseo y a Pirítoo. Por eso - dice la tradición espartana- los atenienses que descienden de Teseo y de Piríteoo, tienen las nalgas pachas.

Con este episodio los atenienses querian elevar a su héroe nacional. Teseo a la categoría de dios olímpico, como Dioniso y Héracles, afirmando que había eludido la muerte. Pero sus enemigos los peloponenses se opusieron con buen éxito, ridiculizando a Teseo. Si los atenienses hubieran sido tan poderosos en tierra como en el mar, sin duda Teseo habría llegado a ser un olímpico o al menos un semidios nacional. Pero Delfos lo impidió al convertirse en fuente poderosa de rivalidad contra Teseo: el Oráculo de Apolo estaba decididamente al servicio de los espartanos en su lucha contra Atenas. (Graves: I, 453-458).

La segunda aventura de los Gemelos está relacionada con la otra hermana de ellos, Clitemnestra. Para protegerla, los Dióscuros debieron enfrentarse con su cuñado Agamenón, y a punto estuvieron de hacer la guerra contra Micenas (Historia Universal Ilustrada: Ibid; Graves: II, 61).

En otra aventura se nos presenta a Cástor y a Pólux actuando no tan caballerosamente. Resulta que Idas y Linceo eran unos gemelos, hijos de Afareo, rey de Mesenia; les llamaban, por eso, los Afáridas. A pesar de ser primos, Idas y Linceo llegaron a ser rivales enconados de los Dióscuros; máxime que tenían cualidades igualmente notables. Idas era más fuerte que Linceo; pero este tenía unos ojos tan penetrantes (de ahí su relación con la vista del lince) que podia ver en la oscuridad, o a través de objetos opacos, o adivinar el paradero de un tesoro enterrado. 
Pues bien, hijas del héroe mesenio Leucipo eran las bellas sacerdotizas Febea e Hileira. Las dos muchachas estaban comprometidas en matrimonio a Idas y a Linceo, pero los Dióscuros se les adelantaron y raptaron a las bellas Leucipidas (o hijas de Leucipo). Algunas representaciones pictóricas muestran a Cástor y a Pólux llevando a cabo el rapto en sendas cuadrigas o utilizando sólo sus respectivos caballos (Rubens). Con Febea e Hileira tuvieron hijos los Dióscuros; y la ofensa inferida a los Afáridas fue la raíz de la rivalidad entre los dos pares de mellizos. (Historia Universal lustrada: XII, 354; Gebhardt: I, 138; Graves: I, 303-304).

Otra aventura en la que intervinieron los Dióscuros tanto como los Afáridas fue la cacería del jabali de Calidón; esta fue convocada por Meleagro, rey de Calidonia (o Calidón); pero ahí, ni Cástor o Pólux, ni Idas o Linceo tuvieron algún papel protagónico. (Graves: I, 326-327; 306; Gebhardt: Ibid.).

Mas importante fue la contribución de los Dióscuros en la expedición de los Argonautas. Iba al mando de la nave Argos el héroe Jasón; y su objetivo era la conquista del vellocino de oro. Durante el viaje, los héroes iban haciendo escalas. En una de ellas, Pólux luchó al pugilato con Amico, un rey famoso como atleta. Pólux lo venció y su triunfo fue más significativo cuanto que Amico era de la progenie de los Gigantes. Los Dióscuros, según esto, representan a los héroes solares o luminosos imponiéndose a los genios de la tempestad o fuerzas más primitivas y caóticas (Gebhardt: Ibid).

Durante la travesía se desató una tremenda tempestad en el mar de Tracia. El buque Argos estaba a punto de zozobrar cuando Orfeo, que iba también embarcado, invocó a los Cabiros de Samotracia, divinidades protectoras de los ravegantes desde los tiempos heroicos. En ese instante aparecieron llamas azuladas sobre la cabeza de los Dióscuros - brillaron dos estrellas en sus frentes, dicen otros- y cesó la tempestad. Desde entonces, Cástor y Pólux pasaron a ocupar el puesto de los Cabiros como protectores de la navegación, y cuando después de su muerte aparecian llamas en los palos de las embarcaciones (fuegos de San Telmo), se suponía que estaban presentes los Dióscuros para calmar la tempestad. (Gebhardt: Ibid; Historia Universal Dustrada: XII, 353). 
Pero la aventura que selló definitivamente la personalidad mítica de los Mellizos ocurrió también durante la travesía de los Argonautas. Olvidada por un momento la rivalidad entre los Dióscuros o Tindáridas y los Afáridas, participaron juntos en una excursión de saqueo en Arcadia. El botín consistía en un hato de ganado. Para repartírselo equitativamente, Idas propuso una estratagema: dividió en cuatro partes una res y dijo que aquel de ellos que devorara primero su porción se quedaría con la mitad del hato; el segundo, se quedaría con la otra mitad. Pero, ni corto ni perezoso, Idas devoró en seguida su parte y ayudó a su hermano a devorar la suya. Luego, los Afáridas se llevaron a Mesenia el botín.

Los Tindáridas fueron a Mesenia y arrebataron el botín; pero, esperando la persecución de los Afáridas, les tendieron a estos una emboscada. Sin embargo, Linceo, desde el monte Taigeto, vio a Cástor escondido detrás de un árbol y se lo dijo a Idas; este descendió rápidamente del Taigeto y con su lanza traspasó el árbol y a Cástor.

Cuando Pólux salió para vengar a su hermano, Idas lo hirió lanzándole una losa o lápida. Malherido, Pólux logró, no obstante, matar a Linceo con su lanza. $Y$ cuando ya Idas estaba a punto de rematar a Pólux, intervino Zeus en favor de su hijo, lanzando un rayo que pulverizó a Idas.

Pólux se acercó a su hermano muerto; levantó los ojos al cielo y se dirigió a su padre Zeus diciéndole que él renunciaba a la inmortalidad que le correspondia por ser hijo suyo, si su hermano Cástor (mortal, por ser mortales sus progenitores) moría. Zeus, entonces, encontró una solución "salomónica": estableció que ambos pasaran alternativamente un día en el cielo y otro en la tierra, o de día uno y de noche el otro; o que un día estén vivos los dos y el siguiente, muertos los dos. (Ruiz de Elvira: 409-410; 475; Gebhardt: I, 139; Graves: I, 306-307). Y para premiar aún más su amor fraterno, Zeus puso las imágenes de Cástor y Pólux entre las estrellas como la constelación de Géminis. (Graves: I, 307).

En la Odisen se hace referencia al encuentro que tuvo Ulises en el inframundo con personalidades como Leda y los Dióscuros. Estos, a pesar de estar en el profundo seno del imperio de los muer- 
tos, cada día y alternativamente renacen a la luz y vuelven a hundirse en la mansión del Erebo. (Gebhardt: lbid).

Fue asi, pues, cómo Cástor y Pólux devinieron catasterizados, e.d., convertidos en constelación. Con ello se corona, a nivel simbólico, un proceso que se estaba dando a nivel práctico en la historia de la Grecia clásica (Siglos V y IV aC.). Los Dióscuros eran héroes tipicamente espartanos. Como estos estaban en pugna permanente con los mesenios (reductos de tribus nativas que quedaron luego de imponerse los dorios-espartanos en el Peloponeso); por eso, los Dióscuros se burlan de los héroes mesenios (roban las hijas de Leucipo) y pelean a muerte contra ellos (representados en los Mellizos Idas y Linceo).

Pero también los espartanos eran enemigos de los atenienses; de ahí que Cástor y Pólux hicieran quedar en ridículo al héroe ateniense Teseo y a su hermano Pirítoo, tal como ya vimos.

El hecho es que los espartanos tuvieron en esa época suficiente poderío militar, de modo que lograron imponer en toda Grecia y aun más allá, el culto de sus héroes Mellizos. Si no hubiera sido así, la constelación de Géminis habría podido conmemorar a otros mellizos famosos, como Héracles e Ificles, o Idas y Linceo, o Acrisio y Preto. (Graves: I, 310).

De los Dióscuros se decía que ayudaban a los espartanos combátiendo junto a ellos bajo la apariencia de jinetes, cabalgando en sendos caballos blancos.

Tanta era la importancia del culto brindado a los Dióscuros, que prácticamente eran patronos de las principales manifestaciones culturales, sobre todo de Esparta. Así, a ellos se consagraban los Juegos Espartanos; se les atribuía la invención de la danza guerrera y la música bélica. Por eso, eran los patronos de los bardos cantores de las batallas.

En las representaciones escultóricas y pictóricas, los Dióscuros aparecen vistiendo del mismo modo; cada uno con su media cáscara de huevo coronada por una estrella (el pileus o gorro lacedemonio); vistiendo clámide púrpura o roja; armados de lanza y montados o al lado de sendos caballos blancos, dados por Posidón o por Hermes. La única diferencia entre ellos es que el rostro de 
Pólux muestra las cicatrices del pugilato.

La más antigua representación de los Dióscuros consistia en dos vigas de madera paralelas, unidas por dos trasversales; se simbolizaba así su amor fraternal. (Graves: I, 309; Historia Universal Ilustrada: XII, 355).

En cuanto a otros atributos de los Dióscuros se dice que Posidón los hizo salvadores de los marineros y náufragos. Para eso, les dio el poder de enviar vientos favorables en respuesta a un sacrificio de corderos blancos ofrecido en la proa de cualquier barco. Cástor y Pólux llegaban seguidos por un séquito de gorriones, o en alas de gorriones, según el Himno Homérico a los Dióscuros. (Graves: I, 308, 312; Gebhardt: I, 140).

Los fosforescentes fulgores que brillan en el mar en tiempo de borrasca, eran anuncio de su llegada para los marinos del Mediterráneo. En aquellos fuegos veía la antigüedad astros móviles o divinidades protectoras de origen sideral. (Gebhardt: Ibid).

Además, en esa constelación de Géminis -compuesta de dos estrellas, de las cuales desaparece una al aparecer la otra- vieron personificados los antiguos la estrella de la mañana y el lucero de la tarde. Incluso para muchos mitólogos, Cástor y Pólux no fueron en su origen más que el Sol y la Luna, concebidos como hermanos gemelos. (Gebhardt: I, 139-140).

Ahora bien, al igual que con otros dioses helénicos, Cástor y Pólux no sólo eran expresión de fenómenos físicos, sino que representaban, además, ciertas ideas morales. Así, bajo su amparo se apelaba a la hospitalidad. Incluso, estaban conectadas a los Dióscuros ciertas festividades en las que la deidad de un templo convidaba a otros dioses vecinos. (Gebhardt: I, 140).

De la Hélade, el culto a los Dióscuros pasó a la Magna Grecia (sur de Italia, Sicilia), de modo que pronto los romanos hicieron suyo también ese culto. Ya en los siglos VI y V aC. se decía que los Dióscuros habían peleado al lado de los romanos en varias importantes batallas. Les fue entonces dedicado un templo, llamado de los Castores, nombre colectivo con que se conocía a Cástor y Pólux. (Gebhardt 140-141. Historia Universal Iustrada: XII, 354-355). 
En Roma, los Mellizos tuvieron los mismos atributos que en Grecia, y aún más. Porque aparecieron en monedas y hasta se dice que estaban presentes en la vida doméstica: los hombres acostumbraban a jurar por Pólux y las mujeres por Cástor. ¡Ecástor!, diría fuera de sí el ama de casa ante un berrinche de su hijo pequeño.

El culto a los Dióscuros se fue extendiendo, a fines del Imperio, a los pueblos conquistados por Roma. Desde el siglo II de nuestra era adquirieron Cástor y Pólux el carácter de divinidades funerarias, quizás por la costumbre de simbolizar la vida en una carrera que empieza en el nacimiento y acaba en la muerte, y en este sentido llegaron a figurar en sarcófagos cristianos. (Historia Universal Mustrada: XII, 355).

Para ir terminando este largo recorrido por las historias que están "contenidas" en las estrellas de Géminis, digamos que faltan aún dos personificaciones más; ambas las recorreremos brevemente. Una, es la que ve en las estrellas "gemelas" a Rómulo y Remo. (Chartrand: lbid.).

La otra ve en Géminis a los gemelos tebanos Anfión y Zetos. De ellos se dice que fueron abandonados aún tierno por su madre en el monte Citerón; pero, recogidos por unos pastores, lograron sobrevivir. Desde niño, Anfión mostró dotes de músico, por lo que Febo le regaló una lira de tres cuerdas.

Ya crecidos, Anfión y Zetos fueron a Tebas, expulsaron al rey Layo y se vengaron de quienes hicieron que su madre los abandonara. Luego, levantaron sin esfuerzo la muralla de la ciudad pues ante los sones de la lira de Anfión, las piedras se amontonaban por sí solas.

Los dos mellizos participaron en la expedición de los Argonautas. Al regresar, fueron muertos por Febo, quien los castigo por desagradecidos. (Graves: I, 318-319). 


\section{Bibliografía}

1 Mark R. Chartatand III. Skyguide. a fiel guide to the heavens. Golden Press. New York. Westem Publishing company. Inc. Racines. Wiscosin, [982.

2. José Luis Cohellas. Ei Universo. Colección Salvat. Temas clave. Salvat Editores, S.A. No 5, Barcelona, 1980 ;

3. Eli de Gortari. En torno a Ja astronomía. Ed. Grijalvo, S.A., México, Barcelona, Buenos Aires, 1982.

4. D. Víctor Gebhardt. Los dioses de Grecia y Roma. I y II. Editora Nacional, S.A., México, 1951.

5. Robert Gaves. Los mitos griegos. I y II. Traducción de Luis Echávarn. \# reimpresión en "El Libro de Bolsillo". Alianza Editorial, S.A., Madrid, 1987.

6. Antonio Ruiz de Elvira. Mitolog ClAsicn. Editorial Gredos, $2^{a}$ Edición, Madrid, 1982.

7. Historia Universal Mustraeda europea americana. XII. Editorial Espasa Calpe, Madrid, 1911.

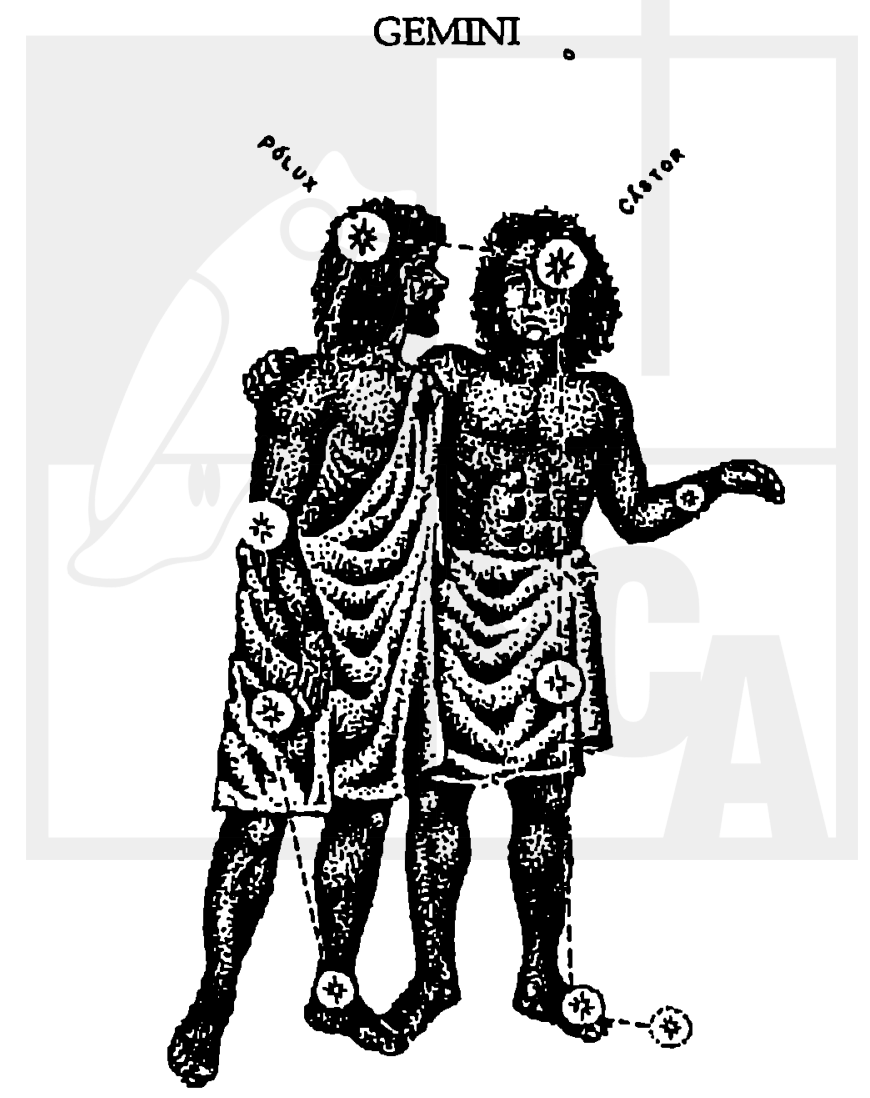

